10

\title{
Оптические свойства отечественного сетчатого стеклоуглерода и его основы
}

\author{
(C) В.В. Черепанов ${ }^{1}$, А.Г. Щурик ${ }^{2}$, Р.А. Миронов ${ }^{3}$ \\ ${ }^{1}$ Московский авиационный институт (Национальный исследовательский университет), \\ 125993 Москва, Россия \\ ${ }^{2} \mathrm{AO}$ „Уральский научно-исследовательский институт композиционных материалов“, \\ 614014 Пермь, Россия \\ ${ }^{3}$ АО „ОНПП “Технология“ им. А.Г. Ромашина“, \\ 249031 Обнинск, Россия \\ e-mail: vvcherepanov@yandex.ru
}

Поступила в редакцию 24.06.2019 г.

В окончательной редакции 26.11.2019 г.

Принята к публикации 16.12.2019 г.

\begin{abstract}
Представлены результаты экспериментальных исследований и математического моделирования некоторых оптических свойств стеклоуглерода и сетчатых материалов на его основе, которые производятся по технологии, разработанной в нашей стране. Исследование было ориентировано на тепловое применение материалов, поэтому основное внимание в нем отводилось определению спектральных характеристик, влияющих на радиационный теплоперенос в сетчатой структуре. Предварительно были созданы плотные образцы, тождественные по физическим свойствам стеклоуглероду основы высокопористых ячеистых углеродных материалов. По экспериментально измеренной спектральной полусферической отражательной способности поверхности образцов при ее нормальном освещении из соотношений Крамерса-Кронига были определены спектры оптических постоянных стеклоуглерода - показателей преломления и поглощения, а также ряд их производных характеристик. Для них в работе даны простые аппроксимирующие соотношения, удобные для инженерных приложений. Полученные спектральные данные были заложены в разработанную ранее оптическую статистическую имитационную модель ультрапористых сетчатых материалов, которая основана на строгой электромагнитной теории и позволяет учитывать как особенности их микроструктуры, так и физические процессы, протекающие в подобных системах на различных пространственных и временных масштабах. Для сетчатого стеклоуглерода, имеющего широкие перспективы применения в качестве конструкционного и теплозащитного материала в аэрокосмической отрасли, представлены примеры расчета спектрально-кинетических коэффициентов переноса излучения, вариантов индикатрисы рассеяния, температурных зависимостей радиационной теплопроводности. Продемонстрированы дополнительные возможности модели.
\end{abstract}

Ключевые слова: стеклоуглерод и сетчатый стеклоуглерод, оптические постоянные, эксперимент, спектрально-кинетические коэффициенты, индикатриса, радиационная теплопроводность, моделирование.

DOI: $10.21883 /$ OS.2020.04.49206.224-19

\section{Введение}

Высокопористые ячеистые материалы на основе стеклоуглерода производят из пенополиуретана (ППУ), который предварительно пропитывается связующим из шликера, содержащего определенный набор углеродных компонент, а затем подвергается температурной деструкция [1-4]. Для производства сетчатого стеклоуглерода используют предварительно ретикулированный ППУ. Шликер при термообработке преобразуется в стеклоуглерод и другие формы углерода, основная часть ППУ выгорает, обеспечивая наличие внутренних скрытых каналов в сетчатой структуре. На заключительном этапе основа пористого материала покрывается несколькими слоями низкотемпературного пироуглерода, осаждаемого на нее из газовой фазы. Эта операция уплотняет поверхность основы и создает некоторые дополнительные свойства результирующего материала, которые и формируют в значительной мере область его практического применения.

Сетчатый стеклоуглерод, (рис. 1), одновременно химически инертен, имеет низкую плотность и теплопроводность, высокую открытую пористость и удельную поверхность, наследуемую от ППУ, обладает жестким пространственным каркасом. Поэтому он применяется в медицине, для изготовления термостойких фильтров и носителей химических катализаторов, аккумуляторов и т. д. Поскольку стеклоуглерод отличается термостойкостью до $3000 \mathrm{~K}$ в вакууме, инертной или восстановительной среде, то его сетчатый вариант может применяться в качестве конструкционного и/или теплозащитного материала в аэрокосмической отрасли.

Для использования сетчатого стеклоуглерода в кислородосодержащей среде при высокой температуре изготавливают специальные сандвич-панели. Его основу защищают специальными покрытиями, например, кар- 


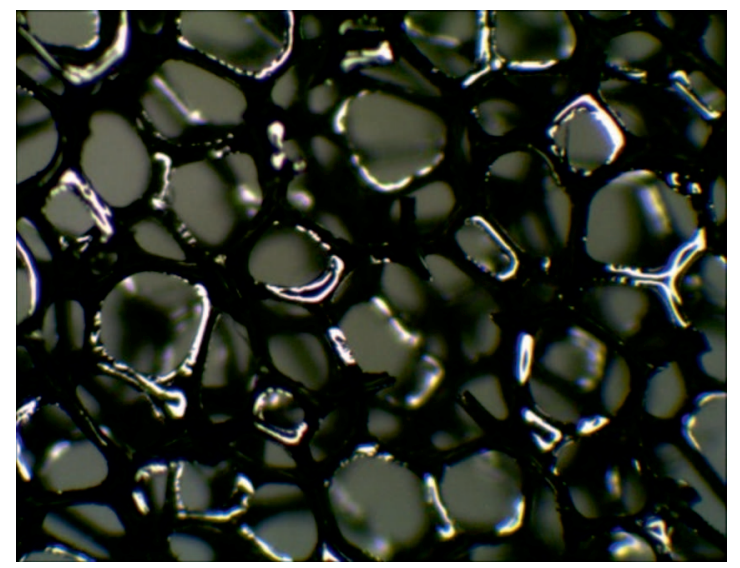

Рис. 1. Фрагмент структуры сетчатого стеклоуглерода.

бидом кремния, осаждаемым на поверхность основы из газовой фазы [4]. Стеклоуглерод - хрупкий материал, поэтому для повышения механической прочности сетчатого каркаса в шликер вносят дополнительные компоненты, например, углеродные нанотрубки [5]. Система открытых пор материала может заполняться тем или иным веществом, способным менять свойства материала, например, подавлять радиационную теплопроводность [4], которая в ультрапористой структуре доминирует при высоких температурах [6]. В этом случае большое значение приобретает процесс взаимодействие фрагментов материала с электромагнитным излучением, для корректного описания которого необходимы спектральные оптические постоянные основы - показатели преломления и поглощения.

Исследование, представленное в работе, не предполагало всестороннее и полное изучение образцов стеклоуглеродных материалов, поскольку это лежит вне поля научных интересов авторов. Стеклоуглерод, пироуглерод, другие углеродосодержащие материалы давно применяются и в некотором отношении изучены достаточно хорошо. Так, информацию о внутренней, фазовой структуре разных форм собственно стеклоуглерода, уже давно производимого в нашей стране, сопутствующих ему углеродосодержащих материалов, о литературных источниках на эту тему можно найти в работах [1,7-14]. Данная работа ориентирована именно на тепловое приложение сетчатого стеклоуглерода и предполагала измерение или расчет таких характеристик его и его основы, которые определяют радиационный теплоперенос в сетчатой структуре. К ним относятся оптические постоянные основы - показатели преломления и поглощения, их производные, а также коэффициенты поглощения и рассеяния излучения, индикатриса рассеяния сетчатого стеклоуглерода. В этом плане исследование является продолжением работ, направленных на создание системы инструментов исследования и прогнозирования свойств перспективных высокотемпературных композиционных материалов для аэрокосмической отрасли [6].
Для определения оптических постоянных твердых тел наиболее удобны образцы с низкой пористостью и гладкой поверхностью. Но исходное сырье, режим термообработки заметно влияют на физические свойства стеклоуглерода и материалов на его основе. Также и свойства подложки, и тепловой режим могут влиять на процесс формирования и свойства поверхностных пленок. Универсальных данных о свойствах композитов подобных сетчатому стеклоуглероду просто не существует. Следовательно, важно, чтобы исследуемый плотный образец был произведен при таких же условиях и из тех же исходных компонент, что и основа анализируемого сетчатого материала.

Имеющаяся технология производства ячеистого стеклоуглерода $[1,2]$ позволяет в зависимости от назначения материала менять в его составе и число углеродных компонентов, и их количественное соотношение друг с другом. В ней как полимерное связующее используется жидкий бакелит марки БЖ-3. Вязкость его суспензии со смесью вводимых углеродных компонентов (порошок природного графита, нанотрубки и пр.) регулируется добавлением пропанола. Однако химическую основу образующихся веществ составляет все-таки бакелит, который и является прекурсором стеклоуглерода. Данная технология была модифицирована так, чтобы пропитанные шликером пластины первичного ППУ можно было бы предварительно сжимать перед термообработкой, добиваясь необходимой плотности. Основные задачи последующего процесса высокотемпературной термообработки, которая, как и для высокопористых материалов, проводится при температуре $175-185^{\circ} \mathrm{C}$, заключались в необходимости образования как можно большей массовой доли стеклоуглерода по всему объему образцов (карбонизация) и получения по возможности более плотной их поверхности. С учетом задач термообработки для нее были сформулированы некоторые оптимизирующие рекомендации [7].

Состав образующих веществ у плотных пластин (таблица) был представлен тремя разновидностями углеро-

Параметры пластин стеклоуглерода, полученных после термообработки сжатых первичных заготовок

\begin{tabular}{c|c|c|c|c|c|c}
\hline № & $\begin{array}{c}\text { РЯ ППУ, } \\
\mathrm{mm}\end{array}$ & $\begin{array}{c}\text { ТП, } \\
\mathrm{mm}\end{array}$ & $\begin{array}{c}\text { ОП, } \\
\mathrm{g} / \mathrm{cm}^{3}\end{array}$ & МД ПУ & МД КГ & МД СУ \\
\hline 1 & 2 & 11 & 0.227 & 0.26 & 0.214 & 0.526 \\
2 & 2 & 6.8 & 0.314 & 0.23 & 0.237 & 0.533 \\
3 & 0.7 & 7.75 & 0.689 & 0.26 & 0.196 & 0.543 \\
4 & 0.8 & 3.5 & 0.809 & 0.205 & 0.208 & 0.587 \\
5 & 0.8 & 2.2 & 1.014 & 0.28 & 0.192 & 0.528 \\
6 & 0.8 & 1.7 & 1.188 & 0.218 & 0.202 & 0.580
\end{tabular}

Примечание. РЯ ППУ - размер ячейки исходного пенополиуретана, ТП - толщина пластины сжатого материала, ОП - объёмная плотность пластины, МД ПУ - массовая доля пироуглерода, МД СУ - массовая доля стеклоуглерода, МД КГ - массовая доля порошка коллоидного графита. 
да, которые также присутствуют и в основе пористых материалов: стеклоуглерод, коллоидный графит и пироуглерод [2]. При этом коллоидный графит был равномерно распределен в стеклоуглероде, возникшем при карбонизации исходной полимерной заготовки из нанесённого на неё связуюшего (сам материал полимерной заготовки при выгорании практически не дает углеродного остатка). Пироуглерод образует плёнку толщиной около $10 \mu \mathrm{m}$ на всей поверхности сетчатой структуры, осаждаясь на нее в реакторе из атмосферы природного метана при температуре, которая меняется в определенном режиме в диапазоне значений $950-1050^{\circ} \mathrm{C}$ на завершающем этапе производства сетчатых образцов. Поэтому и у плотных образцов на завершающей стадии производства поверхность такого же стеклоуглерода также дополнительно уплотнялась пиролитическим углеродом. Тепловые режимы, атмосфера и давление реактора, создаваемые на всех высокотемпературных стадиях, состав исходных компонент при производстве плотных образцов и основы высокопористых образцов, которые определяют их конечную структуру, химический и фазовый состав, были идентичными $[1,2,7]$. Подчеркнем, что уплотнение на стадии полимерной заготовки не меняет свойства плотного материала по отношению к основе сетчатой структуры, а лишь обеспечивает условия, необходимые для удобства определения оптических постоянных.

Представленные в таблице пластины не имеют совершенной плоской поверхности по технологическим причинам. Для исследования спектральных свойств отбирались образцы с наибольшей плотностью поверхности и массовой долей стеклоуглерода. Некоторые результаты исследования стеклоуглерода основы уже освещались в [15]. Однако ниже наряду с оригинальными результатами приводятся также и отдельные результаты этой работы, необходимые для того, чтобы представить более общую картину исследования.

\section{Оптические постоянные основы сетчатых материалов}

Оптические постоянные - спектральные показатели преломления $n$ и поглощения $k$ не поддаются непосредственному измерению. Но они могут быть определены, в частности, по экспериментально измеренной полусферической монохроматической отражательной способности $R=|r|^{2}$ при нормальном освещении поверхности уплотненного образца плоской монохроматической волной $\left(r=|r| e^{i \Theta}-\right.$ комплексный коэффициент отражения поверхности образца). Использовался метод [16], основанный на фундаментальных соотношениях КрамерсаКронига между оптическими постоянными и формуле Френеля [16] для $r$ :

$$
r=|r| e^{i \Theta}=(N-1) /(N+1), \quad N=n_{i} k
$$

Оптические постоянные можно выразить через величину $R$ и фазу коэффициента отражения $\Theta[17]$

$$
n=\frac{1-R}{1+R+2 \sqrt{R} \cos \Theta}, \quad k=\frac{2 \sqrt{R} \sin \Theta}{1+R+2 \sqrt{R} \cos \Theta} .
$$

Эти соотношения являются ключевыми в использованном методе, поскольку величина $\Theta$ в них определяется по вытекающему из формул Крамерса-Кронига дисперсионному уравнению для фазы

$$
\Theta\left(\omega_{0}\right)=\frac{1}{\pi} P \int_{0}^{\infty} \frac{d \ln |r(\omega)|}{d \omega} \ln \left|\frac{\omega+\omega_{0}}{\omega-\omega_{0}}\right| d \omega,
$$

где $P$ обозначает главную часть интеграла. Соотношение (1) можно использовать, если отражательная способность поверхности известна в достаточно широкой спектральной области. Поэтому ее измерения проводились в ближнем и среднем ИК диапазонах $(0.74-20 \mu \mathrm{m})$, которые достаточно надежно перекрывают основную часть носителя функции Планка для значений температуры от комнатной величины и выше.

Исследования проводились на ИК фурье спектрометpe Nicolet iS50 (Thermo Scientific, CША) с интегрирующей сферой IntegratIR (PIKE). В опытах сначала использовался исходный плотный образец с предварительно очищенной поверхностью. Затем поверхность образца шлифовалась, очищалась и измерения повторялись. Шлифовка удаляла пироуглерод с поверхности, она теряла стеклообразный вид, становилась матовой и визуально более похожей на углеродную фольгу. Оптические коэффициенты, определенные для такой матовой поверхности, имели достаточно сложно интерпретируемые значения (в частности, получались отрицательные значения $k$ для отдельных участков спектра), поэтому далее приводятся результаты, полученные только для исходной поверхности образца. Причина такого изменения результатов станет ясной несколько позже.

Коэффициенты $n$ и $k$, определенные по результатам обработки экспериментальных данных для $R$, приведены на рис. 2. По этим данным нетрудно рассчитать компоненты относительной комплексной диэлектрической проницаемости $\varepsilon=\varepsilon_{1}+i \varepsilon_{2}$ стеклоуглерода. Оказалось, что полученные зависимости допускают возможность неплохой качественной аппроксимации значений указанных спектральных характеристик сравнительно простыми соотношениями

$$
\begin{gathered}
n(\lambda)=0.15993 \lambda+3.19453, \\
k(\lambda)=-8.1354 \cdot 10^{-3} \lambda^{2}+0.19425 \lambda+4.44852 \cdot 10^{-2}, \\
\varepsilon_{1}(\lambda)=3.8684 \cdot 10^{-2} \lambda+0.6698 \lambda+3.5459, \\
\varepsilon_{2}(\lambda)=-6.1039 \cdot 10^{-2} \lambda^{2}+1.8160 \lambda+3.5459,
\end{gathered}
$$

в которых $\lambda$ измеряется в микрометрах. На рис. 2 результаты аппроксимации показаны штриховой линией. 


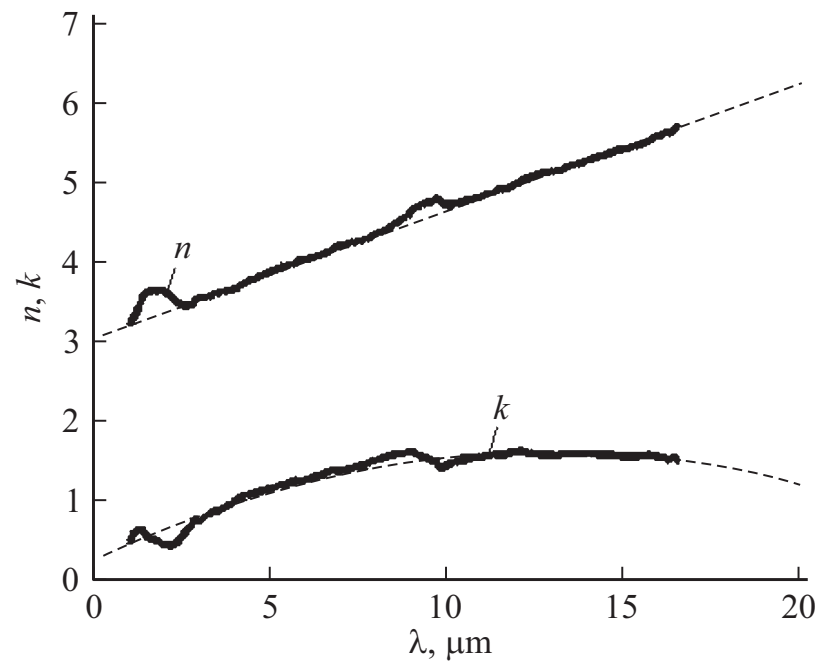

Pис. 2. Спектральные показатели преломления $n$ и поглощения $k$ стеклоуглерода основы, исходная поверхность образца. Штриховая линия - результат интерполяции (2).

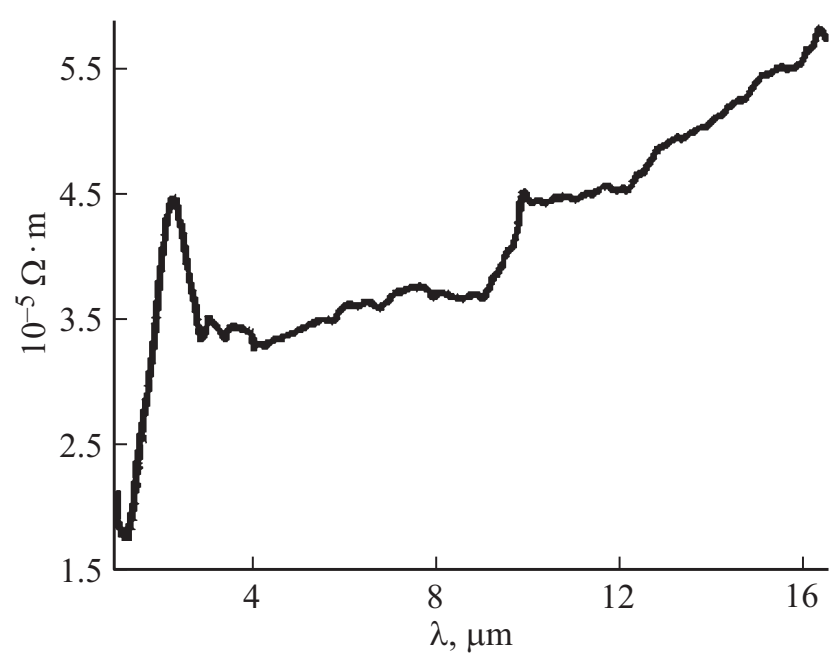

Рис. 3. Спектральная зависимость удельного электрического сопротивления стеклоуглерод.

Соотношения (2) вполне могут применяться при решении ряда инженерных задач. Кроме того, они позволяют провести экстраполяцию соответствующих величин за пределы исследованного экспериментально спектрального диапазона.

Для дополнительного контроля порядка получаемых величин спектральные значения удельного электрического сопротивления $\rho_{e}(\lambda)=2 \pi /\left[c \varepsilon_{2}(\lambda) \varepsilon_{0}\right]$, показанные на рис. 3 , сравнивались с величиной удельного электрического сопротивления стеклоуглерода постоянному току при комнатной температуре. Эта величина определялась по поверхностному удельному сопротивлению, измеренному методом Ван-дер Пау [18] на омметре Щ-307, и имела значение $(63 \pm 8) \cdot 10^{-6} \Omega \cdot \mathrm{m}$, т.е. находилась приблизительно на верхней границе электрического сопротивления графита [19]. Как видим, композит на основе стеклоуглерода обладает электропроводностью, сопоставимой с электропроводностью графита, т. е. настолько высокой, что толщина $\Delta(\lambda)=\left(\varepsilon_{0} c \rho_{e}(\lambda) / \pi\right)^{1 / 2}$ скин-слоя в нем (доли микрометра для рассматриваемой спектральной области) будет значительно меньше не только диаметра узлов и перемычек сетчатой структуры (десятки микрометров), но и толщины поверхностного слоя пироуглерода (около $10 \mu \mathrm{m})$. Именно поэтому попытка отшлифовать поверхность плотного образца столь существенно изменяет результаты определения оптических постоянных. Излучение взаимодействует лишь с поверхностной пленкой пироуглерода в ближней и средней ИК областях спектра. По этой причине внутренней пористостью при определении характеристик радиационного теплопереноса сетчатого стеклоуглерода также можно пренебречь.

\section{Спектрально-кинетические параметры уравнения переноса излучения для сетчатого стеклоуглерода}

В работах [20-22] описаны основные элементы локально-спектральной математической модели ультрапористых неметаллических материалов. В них был предложен метод построения непрерывной пространственной картины взаимодействия электромагнитного излучения с таким достаточно сложным для оптики комбинированным физическим объектом, как представительный элемент, состоящий из ортогональных цилиндров - перемычек и шара - узла. Эти работы позволили создать своеобразный „виртуальный сканер“ - программный инструмент для исследования у подобных объектов их спектров пропускания, рассеяния и поглощения, а также индикатрисы рассеяния. Метод основывался на следующих, достаточно традиционных предположенияx [6,19-22].

1. На пространственных масштабах порядка долей микрометра и выше компоненты падающего поля и поля, рассеянного фрагментами материала, связаны соотношениями строгой электромагнитной теории или, иногда, eе частного следствия - скалярной теории дифракции.

2. Электромагнитная волна, падающая на представительный элемент материала, рассеивается его фрагментами однократно, упруго и независимо в соответствии с теорией Ми. В частности, излучение, рассеянное одним фрагментом, не учитывается в излучении, падающем на другие фрагменты представительного элемента.

3. Принимаются во внимание размеры, состав фрагментов материала и локальные свойства излучения. Среда, в которую погружены фрагменты, не поглощает электромагнитное излучение.

4. Оптические характеристики элемента объема материала, ассоциированного с представительным элементом, определяется, усреднением характеристик отдель- 
ных фрагментов с весами, пропорциональными их сечениям в процессах поглощения и рассеяния излучения.

B [6,23] на примере материалов RVC (Reticulated Vitreous Carbon, CША) была описана математическая модель физических свойств сетчатых неметаллических структур, в которую была интегрирована описанная выше оптическая модель. В этой комбинированной модели сетчатый материал ассоциируется с последовательностью случайных ортогональных представительных элементов (ОПЭ), каждый из которых содержит узел шар и от трех до шести цилиндрических перемычек разной длины и диаметра, ориентированных вдоль декартовых осей глобальной системы координат. Модель построена по следующим ключевым правилам [6].

1. ОПЭ материала генерируются и анализируются последовательно.

2. Учитываются эффективная плотность, анизотропия материала, статистические закономерности его структуры, наличие дополнительных термических и электрических сопротивлений в области контакта фрагментов, флоккул в структуре основы, свойства образующих основу материала веществ.

3. Эффективные свойства ОПЭ рассчитываются по свойствам фрагментов с использованием эквивалентных схем их соединения. Для каждого ОПЭ теплопроводность рассчитывается в рамках изотермического и адиабатического приближений, электрическое сопротивление и диэлектрическая проницаемость - в электростатическом приближении.

4. Каждый новый ОПЭ считается погруженным в эффективную среду, теплофизические свойства которой определяются также и всеми ранее сгенерированными элементами.

5. Для определения оптико-радиационных свойств материала используются как классическая электромагнитная теория, так и квантовая оптика. В расчетах могут применяться как модели интенсивности излучения, так и зависимости, полученные решением кинетических задач переноса излучения.

6. Локальные оптические характеристики материала определяются в рамках модифицированной оптической модели. Она построена на основе упомянутой выше модели независимого взаимодействия с излучением отдельных представительных элементов, но обладает также и инструментом для внесения при необходимости кооперативных поправок в результаты рассеяния излучения отдельными фрагментами [20-22].

Модель обладает определенным набором „степеней свободы“, т. е. содержат неизвестные числовые и функциональные параметры, подлежащие определению в ходе процедуры идентификации по измеренным эффективным оптическим и/или теплофизическим характеристикам материала, полученным на предварительном этапе исследования. Применение модели, идентификация ее параметров позволили исследовать весьма широкий спектр процессов и свойств сетчатых материалов. Однако в указанных работах спектральные свойства

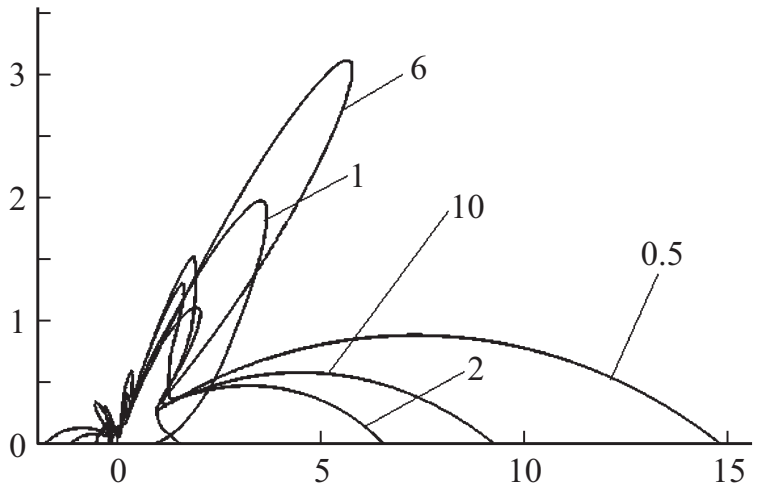

Рис. 4. Индикатрисы рассеяния сетчатого стеклоуглерода при различных значениях длины волны $\lambda T=1300 \mathrm{~K}, g=0.4$, вакуум. Полярные координаты.

стеклоуглерода основы при моделировании не могли быть учтены, поскольку они были неизвестны. Вместо них применялись температурные зависимости электрофизических свойств стеклоуглерода, которые строились по относительно неполным, косвенным данным, доступным из литературы.

В данном разделе представлены некоторые результаты моделирования оптико-радиационных свойств сетчатого стеклоуглерода в вакууме с использование приведенных выше спектральных данных для его основы. Результаты показывают некоторые интересные особенности рассматриваемых материалов, а также демонстрируют уникальные возможности разработанных методов и инструментов при исследовании свойств излучения, сформировавшегося в объеме сетчатой структуры. В расчетах использовались статистические данные о структуре материала с эффективной плотностью $59 \mathrm{~kg} / \mathrm{m}^{3}$ и открытой пористостью 96.1\%, обладающего наиболее высокой степенью ретикуляции из имеющихся образцов. Узлы материала имеют эффективные диаметры от 60 до $200 \mu \mathrm{m}$, перемычки - от 20 до $90 \mu \mathrm{m}$, длины перемычек варьируют от 20 до $480 \mu \mathrm{m}$. ОПЭ освещались с направлений, которые генерировались с учетом задаваемой априори степени анизотропии интенсивности излучения. Применялось распределение Хеньи-Гринстейна, параметр $g$ которого является удобным инструментом управления этим свойством.

На рис. 4,5 в полярных координатах показаны варианты поведения спектральной индикатрисы рассеяния сетчатого стеклоуглерода - функции, практически не изученной в высокопористых материалах. Эти варианты отвечают различным длинам волн и различной степени анизотропии излучения, падающего на образец. Для их получения набиралась статистика $(2-3.5) \cdot 10^{3}$ представительных элементов, время получения каждого отдельного варианта порядка 3-5 min. Представленные индикатрисы относятся к тому же типу функций, что и обсуждаемые в [24], поэтому они также могут быть аппроксимированы достаточно простыми зависимостями 


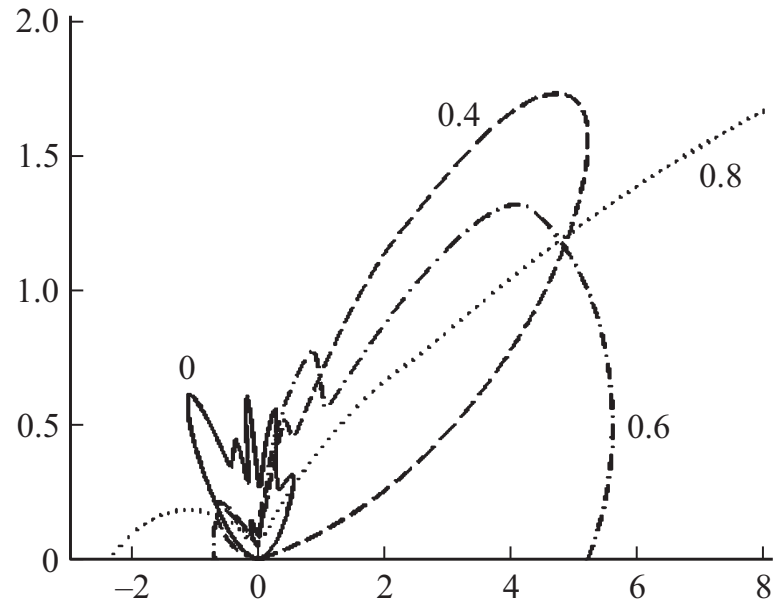

Рис. 5. Индикатрисы рассеяния сетчатого стеклоуглерода в зависимости от параметра $g$ анизотропии излучения. Полярные координаты, $T=1300 \mathrm{~K}, \lambda=1.83 \mu \mathrm{m}$.

приведенного в указанной работе типа. Полярный угол отсчитывался от внутренней нормали к границе слоя.

На рис. 4 показана зависимость спектральной индикатрисы от длины волны $\lambda$ при $T=1300 К$ и $g=0.4$. Указанное значение параметра $g$ анизотропии излучения было выбрано близким к равновесным значениям, полученным ранее при моделировании некоторых волокнистых материалов [6]. Как видно из рисунка, рассеяние излучения материалом носит достаточно избирательный, немонотонный характер, что может иметь целый ряд причин. В частности, материал с указанными выше параметрами плотности и пористости может быть достаточно неоднородным по своим электрофизическим свойствам. Так, в представленных расчетах эффективное удельное электрическое сопротивление системы в направлении, нормальном к границе слоя материала, изменялось в диапазоне $(2.1-6.2) \cdot 10^{-3} \Omega \cdot \mathrm{m}$.

\section{Радиационный теплоперенос в сетчатом стеклоуглероде}

Рисунок 5 показывает влияние параметра $g$ на картину рассеяния сетчатого стеклоуглерода. Результаты относятся к освещению слоя излучением с длиной волны $\lambda \approx 1.83 \mu \mathrm{m}$, определенной из закона смещения Вина для $T=1300 \mathrm{~K}$. Как видим, материал является практически прозрачным для направленного излучения, что вполне объяснимо при столь высокой пористости. Тем не менее рис. 6, $a$ показывает достаточно необычный вариант поведения среднего косинуса $\langle\cos \theta\rangle$ при однократном рассеянии излучения в сетчатом стеклоуглероде с эффективной плотностью $59 \mathrm{~kg} / \mathrm{m}^{3}$. Он уменьшается с ростом показателя анизотропии излучения, а не растет, как этого можно было бы ожидать. Причину этого можно понять, проанализировав рис. $6, b$.
Увеличение степени направленности излучения может заметно повысить интенсивность процесса его рассеяния и величину спектрального показателя рассеяния. Подобное поведение не является, конечно, обязательным для всех вариантов сетчатых структур, в том числе, и для материала с указанной выше плотностью. Некоторое нарушение монотон-ности такого поведения при длине волны $\lambda$, близкой к $0.5 \mu \mathrm{m}$, связано с иногда возникающей необходимостью увеличения объема выборки представительных элементов в статистическом методе при приближении $\lambda$ к области ближнего ультрафиолета. В приведенном примере усиление рассеяния не в состоянии компенсировать рост проникающей способности излучения при увеличении степени его направленности, о чем говорит поведение радиационной теплопроводности на рис. 7.

Радиационная теплопроводность материала рассчитывалась по известным соотношениям [6]

$$
\begin{aligned}
\lambda_{r}(T) & =\frac{8 \pi k_{\mathrm{L}}^{4} T^{3}}{3 c^{2} \hbar^{3}} \int_{0}^{\infty} \frac{1}{\alpha_{\lambda}+\beta_{\lambda}^{*}} \frac{u^{4} e^{-u}}{\left(1-e^{-u}\right)^{3}} d u \\
& =\frac{8 \pi k_{\mathrm{L}}^{4} T^{3}}{3 c^{2} \hbar^{3}} \int_{0}^{\infty} \frac{1}{\alpha_{\lambda}+\beta_{\lambda}^{*}} \frac{\tau^{-6} e^{-1 / \tau}}{\left(1-e^{-1 / \tau}\right)^{3}} d \tau \\
& =\frac{1.1640285 T^{3} n_{g}^{2}}{10^{8}}\left(\int_{0}^{1} \frac{1}{\alpha_{\lambda}+\beta_{\lambda}^{*}} \frac{u^{4} e^{-u}}{\left(1-e^{-u}\right)} d u\right. \\
& \left.+\int_{0}^{1} \frac{1}{\alpha_{\lambda}+\beta_{\lambda}^{*}} \frac{\tau^{-6} e^{-1 / \tau}}{\left(1-e^{-1 / t a u}\right)^{3}} d \tau\right),
\end{aligned}
$$

в которых $\alpha_{\lambda}, \beta_{\lambda}, \beta_{\lambda}^{*}=\beta_{\lambda}(1-\langle\cos \rangle)-$ спектральные коэффициенты поглощения, рассеяния и транспортный коэффициент рассеяния соответственно; $n_{g}$ - показатель преломления среды, окружающей каркас. Остальные обозначения стандартные. Последний вариант соотношений (3) позволяет обойти проблему вычисления несобственных интегралов в ходе моделирования.

Температурные зависимости радиационной теплопроводности (3) сетчатого стеклоуглерода в вакууме при различной степени асимметрии $g$ падающего на материал излучения приводятся на рис. 7. Как видно, полная теплопроводность и ее компоненты не являются свойствами высокопористых материалов, поскольку они существенно зависят от физических условий, в которых материал находится [6]. Рисунок наглядно демонстрирует это обстоятельство.

Верификация значений радиационной теплопроводности в использованном методе исследования проводится по результатам сравнения значений полной теплопроводности, полученной для материала в результате моделирования и по результатам обработки данных нестационарного теплового эксперимента с образцами материала $[6,23,25,26]$. Уже значения для кривой 1 на 

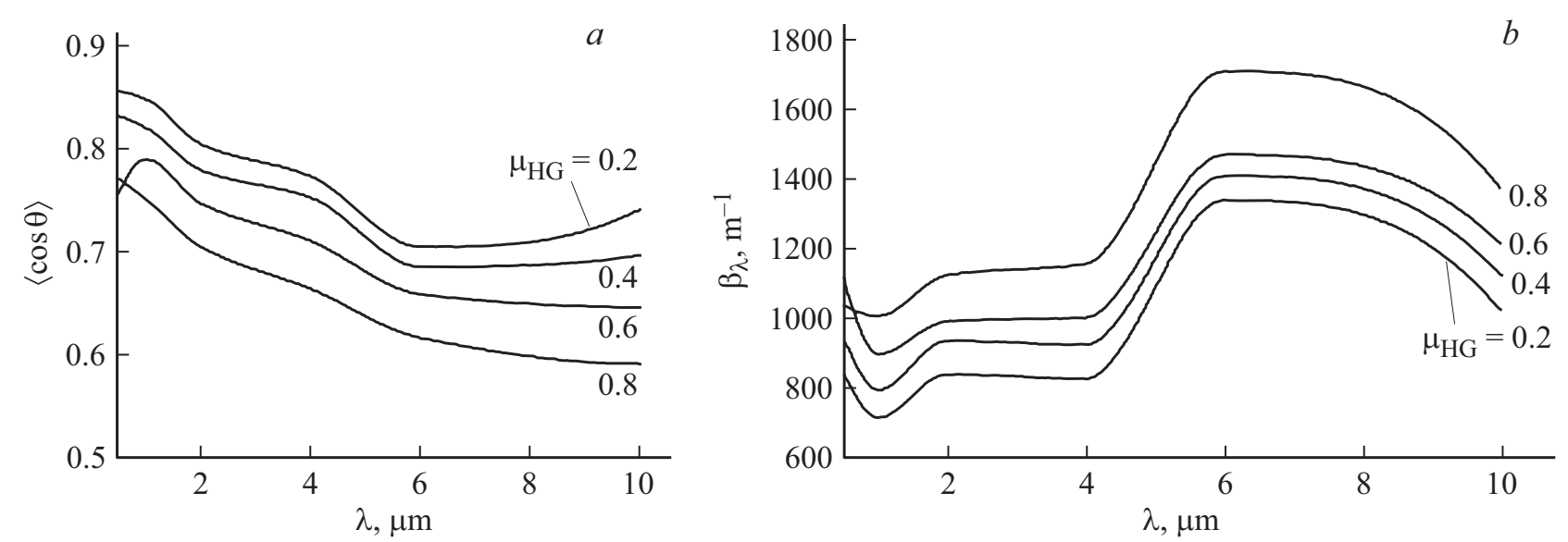

Рис. 6. Спектральные средний косинус $(a)$ и коэффициент рассеяния $(b)$ сетчатого стеклоуглерода при различных значениях параметра анизотропии $\mu_{\mathrm{HG}}=g$ излучения.

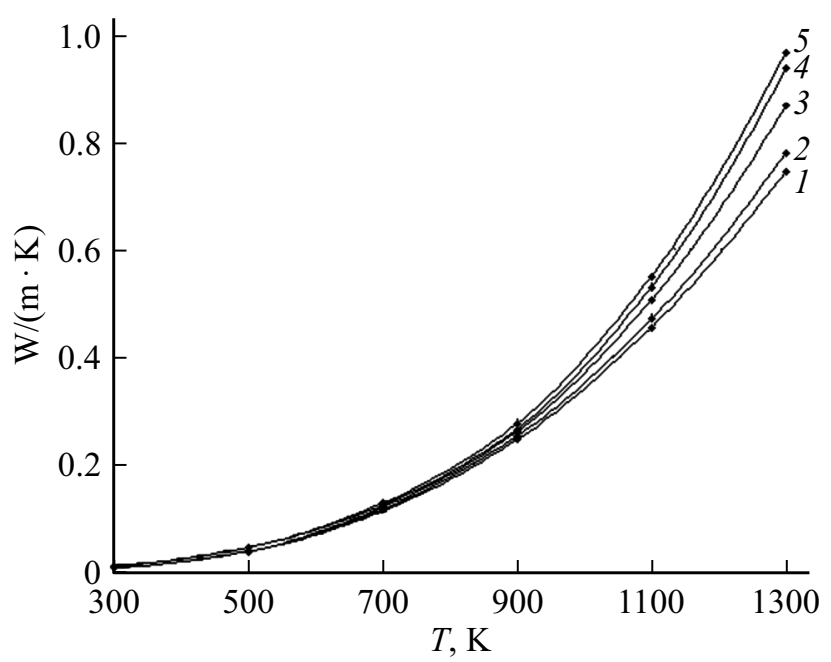

Рис. 7. Рассчитанные значения радиационной теплопроводности сетчатого стеклоуглерода с плотностью $59 \mathrm{~kg} / \mathrm{m}^{3}$. Кривые $1,2,3,4,5$ соответствуют $g=0 ; 0.2 ; 0.4 ; 0.6 ; 0.8$.

рис. 7 (которая в наибольшей степени отвечает условиям теплового эксперимента) приводит к примерно 5\% завышению рассчитанных значений полной теплопроводности по сравнению с экспериментальными результатами. Однако заметим, что представленные на рис. 7 значения рассчитаны для случая полной ретикуляции. Наличие остаточных мембран в реальном материале радиационную теплопроводность, конечно, снижает. Поэтому представленные результаты расчета радиационной теплопроводности являются для реальных материалов сравнительно неплохой верхней оценкой, достаточно точной для ряда инженерных приложений.

В заключение отметим, что каждое из рассчитанных значений теплопроводности было получено после усреднения результатов трех серий расчетов, в каждой из которых было сгенерировано около $3 \cdot 10^{3}$ представительных элементов. Практика моделирования показывает, что именно подобная организация расчетов в методе $[6,23]$ позволяет при относительно небольших объемах выборки снизить статистическую погрешность метода, обусловленную характеристиками начальных элементов сгенерированной последовательности, и более предпочтительна, чем одиночные расчеты на сопоставимой суммарной статистике $\left(\sim 10^{4}\right)$.

\section{Заключение}

Получены новые важные данные об оптических постоянных и связанных с ними величинах производимого в нашей стране стеклоуглерода. Произведена оценка скин-слоя и уточнен механизм взаимодействия электромагнитного излучения с фрагментами композиционных сетчатых материалов на его основе. В частности, было показано, что в таких материалах взаимодействует с электромагнитным излучением лишь поверхностный слой пироуглерода, что внутренняя закрытая пористость, присущая сетчатому стеклоуглероду, не влияет на этот процесс. Для этих материалов были рассчитаны и исследованы радиационно-кинетические коэффициенты переноса излучения, индикатриса, радиационной теплопроводность в широком диапазоне параметров, определяющих внешние условия. Было показано, в частности, что параметры кинетического уравнения, радиационная и полная теплопроводности не могут считаться свойством таких материалов, поскольку они в значительной степени зависят от внешних условий, например от анизотропии падающего излучения. Моделирование позволяет увидеть величину такого влияния. В реализованном методе применялись как известные, зарекомендовавшие себя экспериментальные подходы, так и оригинальные эффективные инструменты теоретического исследования, анализа и прогнозирования свойств материалов. Они позволяют адекватно моделировать теплообмен, существенно снизить затраты на 
разработку новых перспективных материалов и изделий из них.

\section{Финансирование работы}

Работа выполнена при финансовой поддержке Российского научного фонда в рамках проекта 18-19-00492.

\section{Конфликт интересов}

Авторы заявляют, что у них нет конфликта интересов.

\section{Список литературы}

[1] Щурик А.Г. Искусственные углеродные материалы. Пермь: Изд-во Пермского гос. ун-та, 2009. 342 с.

[2] Щурик А.Г. Патент РФ № 2089494, 1997.

[3] Klett J.W. United States Patent № 6033506, 2000.

[4] Ultramet, USA. Reticulated Vitreous Carbon Foam. [Электронный ресурс] Режим доступа: https://ultramet.com/refractory-ope-cee-foams/reticulatedvitreous-carbon-foam

[5] Щурик А.Г., Докучаев С.В., Петров В.А. // Актуальные проблемы порошкового материаловедения. Сб. трудов международной науч.-техн. конференции, 26-28 ноября 2018. Пермь: Изд-во Пермского нац. исслед. политехн. унта, 2018. С. 522.

[6] Алифанов О.М., Черепанов В.В. Методы исследования и прогнозирования свойств высокопористых теплозащитных материалов. М.: Изд-во МАИ, 2014. 264 с.

[7] Щурик А.Г. // Актуальные проблемы порошкового материаловедения. Сб. трудов международной научно-техн. конференции, 26-28 ноября 2018. Пермь: Изд-во Пермского нац. исслед. политехн. ун-та, 2018. С. 516.

[8] Свойства материалов на основе углерода в интервале температур 50-3500 К / Под ред. Ануфриевой Ю.П. М.: Изд-во НИИГРАФИТ, 1971. 200 с.

[9] Фиалков А.С. Углеграфитовые материалы. М.: Энергия, 1979. $320 \mathrm{c}$.

[10] Шулепов С.В. Физика углеграфитовых материалов. М.: Металлургия,1990. $336 \mathrm{c.}$

[11] Плешаков В.Ф., Ланцова С.А. // Химия твёрдого топлива. 1992. № 6. C. $135-139$.

[12] Щурик А.Г., Чунаев В.Ю., Чечулина Е.А. Теплофизика и структура ячеистых углеродных материалов. Материалы XVI Всероссийской научно-техн. конференции. Пермь: Изд-во Пермского нац. исслед. политехн. ун-та, 2015. C. $111-115$.

[13] Беленков Е.A. // Неорганические материалы. 2001. Т. 37. № 9. C. 1094-1101.

[14] Песин Л.А. и др. // ФТТ. 1992. Т. 34. № 6. С. 1734-1739.

[15] Черепанов В.В., Щурик А.Г., Миронов Р.А. // Тепловые процессы в технике. 2018. Т. 10. № 7-8. С. 317-324.

[16] Musfeldt J.L., Tanner D.B., Paine A.J. // J. Opt. Soc. Am. A. 1993. V. 10. N 12. P. 2648-2657.

[17] Bohren C.F., Huffman D.R. Absorption and Scattering of Light by Small Particles. NY.: Wiley, 1998. 545 p.; Борен K., Хафмен Д. Поглощение и рассеяние света малыми частицами. 1986. М.: Мир, 664 с.

[18] Van der Pauw L.J. // Phillips Research Reports. 1958. V. 26. N 8. P. $220-224$.
[19] Kaye G.W., Laby T.H. Tables of physical and chemical constants and some mathematical functions. London, NY, Toronto: Longmans, Green \& Co, 1911. 161 p.; Кей Джс., Лэби T. Таблицы физических и химических постоянных. М.: Государственное издательство физико-математической литературы, 1962. 248 с.

[20] Черепанов В.В. // Тепловые процессы в технике. 2011. Т. 3. № 5. C. 215-227.

[21] Алибанов О.М., Черепанов В.В. // Математическое моделирование РАН. 2012. Т. 24. № 3. С. 33-47.

[22] Cherepanov V.V. et al. // Applied Mathematical Modelling. 2016. V. 40. N 5-6. P. 3459-3474. doi 10.1016/j.apm.2015.03.040

[23] Алифанов О.М., Черепанов В.В., Моржухина А.В. // Инженерно-физический журнал. 2015. Т. 88. № 1. C. 122-132; Alifanov O.M., Cherepanov V.V., Morzhukhina A.V. // Journal of Engineering Physics and Thermophysics. 2015. V. 88. N 1. P. 124-133. doi $10.1007 / \mathrm{s} 10891$ 015-1174-x

[24] Мищенко М.И. Электромагнитное рассеяние в случайных дисперсных средах: Фундаментальная теория и приложения. Дисс. д.ф-м.н. Киев, Нью-Йорк: Национальная академия наук Украины. Главная астрономическая обсерватория. Национальное управление аэронавтики и исследования космического пространства США. Годдардовский институт космических исследований, 2007. 317 с.

[25] Alifanov O.M. Invers heat transfer problems. Berlin, Heidelberg, New York, London, Paris, Tokyo, Hong Kong, Barcelona, Budapest: Springer-Verlag, 1994. 274 p.

[26] Alifanov O.M., et al. // Proc. 7th International Conference on Inverse Problems in Engineering (ICIPE 2011), May 4-6, 2011, Orlando, Florida, USA, P. 173-178. doi 10.13140/RG.2.1.1686.4723 